\title{
CALIDAD DE VIDA LABORAL EN LOS MUNICIPIOS DE CHILE: EL CASO DE LA MUNICIPALIDAD DE LO BARNECHEA.
}

Macarena Yáñez Correa ${ }^{39}$.

\section{RESUMEN}

Desde hace algunas décadas se ha venido estudiando la Calidad de Vida como una preocupación social, debido a los cambios se han ido provocando en las organizaciones, la economía, la administración y el control de mercados internos. Junto con ello, los cambios políticos, económicos y culturales que se han estado viviendo, generan nuevos espacios de reflexión y obligan a las organizaciones a modernizarse y con ello, fortalecer la gestión de recursos humanos y la gestión de personas. Lo señalado anteriormente, hace necesario la preocupación por la calidad de vida laboral y en especial de los funcionarios públicos que tienen como desafío entregar servicios públicos de calidad. En este marco se realizó una investigación sobre la calidad de vida laboral en la Municipalidad de Lo Barnechea, con la colaboración del Instituto Chileno de Estudios Municipales de la Universidad Autónoma de Chile.
Palabras clave: Calidad de Vida - Clima laboral - Condiciones de Satisfacción - Organización Municipal.

\section{ABSTRACT}

For some decades it has been studying the Quality of Life as a social concern, because of changes have been causing in organizations, an economy, management and control of internal markets. Along with this, the political, economic and cultural changes that have been living, create new spaces for reflection and force organizations to modernize and thus, strengthen the management of human resources and people management. The foregoing, requires the concern for the quality of working life and especially of public officials, whose challenge is deliver quality public services. In this framework, conducted research on the quality of working life in the Comunne of Barnechea, with the collaboration of the 
Instituto Chileno de Estudios Municipales at the Universidad Autónoma de Chile.

Keywords: Quality of Life - Work climate - Conditions of Satisfaction Municipal Organization.

\section{INTRODUCCIÓN}

El presente artículo contiene los resultados de un estudio de investigación relativo a la calidad de vida laboral realizado en la Municipalidad de Lo Barnechea en el marco del desarrollo de propuestas para la innovación en la gestión de municipal.

En la gestión moderna de las instituciones $\mathrm{u}$ organizaciones, la Calidad de Vida Laboral (CVL) ha cobrado especial importancia por cuanto los niveles de satisfacción y las posibilidades de desarrollo personal de los funcionarios o empleados se encuentran asociadas a los mayores grados de productividad (eficacia y eficiencia). Esto ha llevado a los equipos directivos y empresarios a impulsar un conjunto de acciones que pongan en el centro de la gestión el mayor grado de satisfacción de los empleados. Estas estrategias se han desarrollado primero en los espacios privados y paulatinamente se han trasladado al ámbito público, como siempre, el traslado de los modelos desde el mundo privado al público tiene complejidades y requiere de ajustes, de lo que pretende dar cuenta este estudio.

\section{I.- ORIGEN DEL ENFOQUE DE CALIDAD DE VIDA LABORAL}

La preocupación sobre la calidad de vida en los espacios de trabajo surge en el escenario de postguerra en Estados Unidos y Europa, las corrientes de pensamiento existencialistas y fenomenológicas abrieron la puerta para la discusión sobre la condiciones de vida de la personas ya no sólo en los espacios privados sino también públicos. Por su parte en el plano social la crítica a las rígidas estructuras laborales en las primeras décadas del siglo XX había tenido impacto en el desarrollo de una legislación que promovía los derechos laborales. Ambos tendencias en el plano del pensamiento y de los derechos del trabajo adquieren un nuevo impulso con el movimiento medio ambiental que pone en el tapete la búsqueda de una mejor Calidad de Vida Laboral (CVL). El foco ahora estaba dirigido al ámbito organizacional y los reclamos se acentuaron sobre las condiciones medioambientales, la salud, las remuneraciones, jornadas de trabajos, seguridad laboral, entre otras.

Al revisar el origen del concepto de Calidad de Vida Laboral se observan controversias entre autores respecto al periodo en que se acuña el término, hay quienes plantean que nació en la década de los 50' con la expansión de este movimiento por Estados Unidos y por los países desarrollados con los objetivos entre otros de minimizar las lesiones, muertes y daños psicológicos que impactan en la salud física de los trabajadores. (González, Yoshimatsu, y Cantú, 2000). Por su parte otros autores plantean que 
el concepto de CVL surgió en los años 60' (Inglehart, 1999) con temas ligados al medio ambiente y al deterioro de las condiciones de la vida urbana $y$, el interés por conocer las consecuencias del de la CVL en la industria sobre el bienestar humano.

Más allá de esta controversia, el concepto de CVL lo encontramos consolidado como ámbito de estudio y espacio de intervención hacia fines de la década de los 70' e inicios de los 80 ', en este periodo se observa una distinción al interior del concepto entre los elementos vinculados a las condiciones objetivas - asociada a elementos materiales - y los componentes subjetivos, lo cual significó la síntesis de todas las áreas de la vida de la persona en su interior (GómezVela y Sabeh, 2002).

Durante los años $80^{\prime}$ el término Calidad de Vida, se adoptó como un tema sensibilizador que podría ofrecer a los profesionales de distintas disciplinas un lenguaje común y guiar las prácticas de las empresas, más orientados ahora hacia la persona, su autodeterminación y el logro de una mayor satisfacción con su vida. A lo largo de los años 90' el concepto CVL tuvo una evolución logrando perfeccionarse desde el punto de vista metodológico, esto significó un desarrollo de procesos de intervención en los espacios laborales con la consecuente adopción de técnicas de mejora en sus procedimientos e intervenciones (Gómez-Vela y Sabeh, 2002).
Desde los años $90^{\prime}$ hasta la actualidad, la CVL se ha caracterizado por la preocupación de temáticas como la satisfacción que el trabajo le genera a la persona, además de la preocupación de la organización por mantenerse más cercanos a los trabajadores y centrarse en el estudio del individuo (Heskett, 1994; Fernández Ríos, 1999). Por otra parte, también hay influencia en la nueva forma de gestionar los Recursos Humanos, que conceden un papel destacado a las organizaciones para promover la Calidad de Vida Laboral (Munduate, 1993; de la Poza, 1998; Lau 2000).

En síntesis en este proceso de desarrollo - entre los años 1950 y 2000- y con la popularización del movimiento, los análisis sobre CVL que se inician ligados al Desarrollo Organizacional se alejan progresivamente de estos planteamientos para incorporar los aportes del enfoque sociotécnico y de la Democracia Industrial (Walton, 1973; Davis y Cherns, 1975; Suttle, 1977; Nadler y Lawlwe, 1983; Delamotte y Takezawa, 1984). Es en este escenario que la necesidad de Humanizar el Entorno de Trabajo sustentó la posición de prestar mayor atención al factor de Desarrollo Humano, en la mejora de su Calidad de Vida. 
II.- CALIDAD DE VIDA LABORAL: CONCEPTO MULTIDIMENSIONAL Y ORGANIZACIONES MODERNAS

Detrás de esta breve revisión del origen del concepto de CVL es posible observar interpretaciones diversas sobre su naturaleza, especialmente marcadas por la evolución histórica de las disciplinas que le dan sustento al constructo (Administración, Gestión de organizaciones, Psicología Laboral, Psicología Organizacional entre otras), lo que dificulta el desarrollo de un concepto común y la comprensión de las implicancias prácticas para las organizaciones o instituciones, se destacan en este sentido antinomias en su definición o naturaleza (filosofía general o plan de acción; se mide desde lo objetivo o subjetivo; involucra el funcionamiento interno o también los usuarios; se orienta al beneficio del individuo o a la organización).

Algunas de estas antinomias en nuestra opinión son sólo aparentes por ejemplo la medición en torno a elementos objetivos (equipamiento, infraestructura y productos desarrollados por la empresa) (Casas, 1998), y subjetivos (proceso de construcción sociocognitivo que se refiere al conjunto de percepciones, expectativas y de experiencias laborales, integrándose lo individual y lo colectivo). Esta última dimensión abarca un conjunto de políticas y estrategias que engloban todos los esfuerzos por incrementar la productividad, optimizar las organizaciones y los puestos de trabajos, además de mejorar la motivación de las personas (De la Poza, 1998). La distinción objetivo/subje- tivo sólo una distinción para separar aspectos de la medición, ya que tanto aquellos denominados objetivos y subjetivos son evaluados desde la construcción del propio actor (funcionario); esto no significa que los elementos objetivos no puedan ser medidos, por ejemplo, la tasa de metros cuadrados por funcionario, sino que el nivel de satisfacción depende de las expectativas de los propios funcionarios. Se entiende que existe un piso mínimo de condiciones materiales para la producción, pero ellas se encuentran mediadas por las características del contexto y las expectativas de los funcionarios.

Otra de estas antinomias es la orientación al sujeto o a la organización autores como (Davis y Cherns, 1975; Taylor, 1978; Elizur y Shye, 1990; González et al., 1996) abordan dos perspectivas teóricas; Perspectiva de la calidad del entorno de trabajo y la Calidad de Vida Laboral Psicológica. Ambos enfoques comparten la meta de mejorar la Calidad de Vida Laboral, sin embargo existen discordancias manifiestas en cómo se logra la Calidad de Vida, por ejemplo la perspectiva denominada CVL psicológica persigue fundamentalmente la satisfacción, la salud y el bienestar del trabajador, anteponiendo los intereses individuales a los de la organización. Por otro lado, tenemos que la perspectiva CVL del entorno de trabajo tiene la postura de alcanzar una mayor productividad y eficacia organizacionales, con el que se obstaculizaría satisfacer las demandas y necesidades de cada trabajador. En este punto consideramos que la naturaleza pro- 
pia de la CVL se encuentra en la capacidad relacional de equilibrar condiciones de trabajo y productividad en el entorno de trabajo, el propósito no es priorizar la dimensión personal u organizacional, por cuanto se desnaturaliza la relación básica que vincula a ambos aspectos.

En esta perspectiva nos encontramos más cerca de las propuestas actuales que aprecian la CVL como un proceso dinámico y continuo para incrementar la libertad de los empleados en el puesto de trabajo mejorando la eficacia organizacional y el bienestar de los trabajadores a través de intervenciones de cambio organizacional planificadas, que incrementarán la productividad y la satisfacción. (Sun 1998). Desarrollos recientes asumen estos desafíos como el modelo Best Place To Work, el que busca conseguir el mejor lugar para trabajar atendiendo las necesidades de los clientes internos y externos, pretendiendo alcanzar mayores niveles de eficiencia y eficacia (GPWI España: Best Workplaces - España 2003- 2005).

En esta perspectiva los ejes fundamentales que aparecen definiendo la CVL son satisfacción y posibilidades de desarrollo personal, planificación del cambio organizacional $y$, el elemento común a todos los enfoques aumento de la productividad (eficiencia y eficacia).

\section{III.- DESCRIPCIÓN DEL ESTUDIO}

El nivel de estudio propuesto para la investigación fue de carácter descriptivo de tipo censal, a partir del cual se podría caracterizar las percepciones respecto a un conjunto de dimensiones que consideramos relevantes par la medición de la CVL. Se convocó a todos los funcionarios del municipio de Lo Barnechea (información entregada por la municipalidad), que se encontraban desempeñando funciones en el período del levantamiento de la información. EL total de funcionarios que participó de la evaluación fueron 243.

Para la medición se utilizó un cuestionario construido a través de preguntas que recogían las percepciones respecto a nueve dimensiones que constituyen a nuestro entender los elementos centrales de la calidad de vida laboral. Las dimensiones consideradas fueron:

\section{- Estructura Física}

- Entorno Ambiental

- Clima Laboral

- Liderazgo

- Incentivos

- Organización del trabajo

- Tiempo

- Satisfacción en el puesto de trabajo

- Vinculación trabajo y vida familiar

Estas percepciones se midieron haciendo uso de la Escala Likert. ${ }^{40}$

\footnotetext{
40 “El escalamiento tipo Likert fue desarrollado por Rensis Likert y consiste en un conjunto de ítems presentado en forma de afirmaciones o juicios, frente a los cuales se pide la reacción de los sujetos. Se presenta cada afirmación y se pide al sujeto que elija una de las siguientes cuatro opciones: "Muy de acuerdo", "De acuerdo", “En desacuerdo" $y$ "Muy en desacuerdo". A cada punto se le asigna un valor numérico. Así, el sujeto obtiene una puntuación respecto a la afirmación, y al final se obtiene su puntuación total sumando las puntuaciones obtenidas en relación a todas las afirmaciones. Las afirmaciones califican al objeto de actitud que se está midiendo y deben expresar sólo una relación lógica, es muy recomendable que no excedan de 20 palabras." (en Hernández, R. y Fernández, C. METODOLOGÍA DE LA INVESTIGACIÓN SOCIAL. Mc Graw Hill, México, 2001, p.256)
} 
El análisis de la información contempla un análisis de carácter descriptivo y consiste en la obtención de diferentes estadísticos de escala y de dispersión que permitan tener una primera visión de los resultados que se generen. Entre los estadísticos de escala a utilizar se encuentra la moda (valor más frecuente), percentiles (valores de la variable en agrupaciones de los datos, la más conocida es la mediana que corresponde al percentil 50), promedio, distribuciones de frecuencia, etc. En el caso de los estadísticos de dispersión se hará uso de la desviación estándar (dispersión en torno al promedio), rango (diferencia entre el mínimo y el máximo), valor mínimo, valor máximo, coeficiente de variación, etc.

A partir de la utilización de la escala Likert, se construyó una metodología para conocer el grado de satisfacción que poseen los funcionarios con respecto a las dimensiones analizadas.
El análisis de resultados consistió en identificar el grado de satisfacción de los funcionarios a partir de la sumatoria de los puntos correspondientes a cada respuesta, en relación al máximo posible de obtener (sumatoria de Muy de Acuerdo en todas las preguntas). Esta sumatoria de puntos se estandariza en un rango entre 0 y 100 , para hacer comparable los valores en las diferentes partes de la encuesta, $y$ no dependa el valor total de puntos a obtener del número de preguntas.

Es decir, un indicador logra unos 100 puntos de satisfacción cuando la sumatoria del nivel de satisfacción de todas las preguntas de las encuestas, es igual al máximo puntaje posible de obtener en todas las respuestas de todas las encuestas. Así, las respuestas con muy de acuerdo corresponde a 4 puntos, de acuerdo a 3 puntos, en desacuerdo a 1 puntos y muy en desacuerdo a 0 puntos. Se excluye los 2 puntos por no existir la categoría ni de acuerdo - ni en desacuerdo.

En el rango de 0 - 100 se pueden establecer puntos de corte que clarifiquen el análisis

\begin{tabular}{|c|l|}
\hline Puntaje 0 & $\begin{array}{l}\text { Significa que en todas las preguntas consultadas, el funcionario } \\
\text { declaro estar muy en desacuerdo. }\end{array}$ \\
\hline Puntaje 25 & $\begin{array}{l}\text { Significa que en todas las preguntas consultadas, el funcionario } \\
\text { declaro, en promedio, estar en desacuerdo. }\end{array}$ \\
\hline Puntaje 50 & $\begin{array}{l}\text { Significa que la intensidad de respuestas asociadas al } \\
\text { desacuerdo están contrapesadas con la intensidad de } \\
\text { respuestas asociadas al acuerdo. }\end{array}$ \\
\hline Puntaje 75 & $\begin{array}{l}\text { Significa que en todas las preguntas consultadas, el funcionario } \\
\text { declaro, en promedio, estar de acuerdo. }\end{array}$ \\
\hline Puntaje 100 & $\begin{array}{l}\text { Significa que en todas las preguntas consultadas, el funcionario } \\
\text { declaro estar muy de acuerdo. }\end{array}$ \\
\hline
\end{tabular}


Por último, para las preguntas componentes de las dimensiones se obtendrán los porcentajes de respuestas de los funcionarios con respecto a las categorías muy de acuerdo y acuerdo de las afirmaciones consultadas.

\section{IV.- RESULTADOS}

En el presente apartado, se revelan los principales resultados obtenidos del estudio de calidad de vida laboral levantado para el municipio de Lo Barnechea. En este acápite se presentaran los resultados por variables para las condiciones materiales y condiciones organizacionales, desagregadas en sus variables componentes.

\section{Análisis condiciones materiales y condiciones organizacionales}

Como se ha señalado anteriormente, la evaluación de la calidad de vida al interior del municipio de Lo Barnechea ha sido construida sobre:

- La percepción de los funcionarios hacia las condiciones físicas y ambientales del lugar donde desempeñan su trabajo por una parte; $y$

- Las apreciaciones sobre las formas de interacción laboral.

Según los datos mostrados en el gráfico de comparación de medias de puntajes para la calidad de vida laboral en la Municipalidad de Lo Barnechea, es posible observar que los funcionarios realizan evaluaciones positivas en la mayoría de los aspectos, destacando el Clima Laboral, Satisfacción en el puesto de trabajo y Uso del Tiempo.

Gráfico n¹. Calidad de vida laboral. Nivel de Satisfacción Ptje 0-100

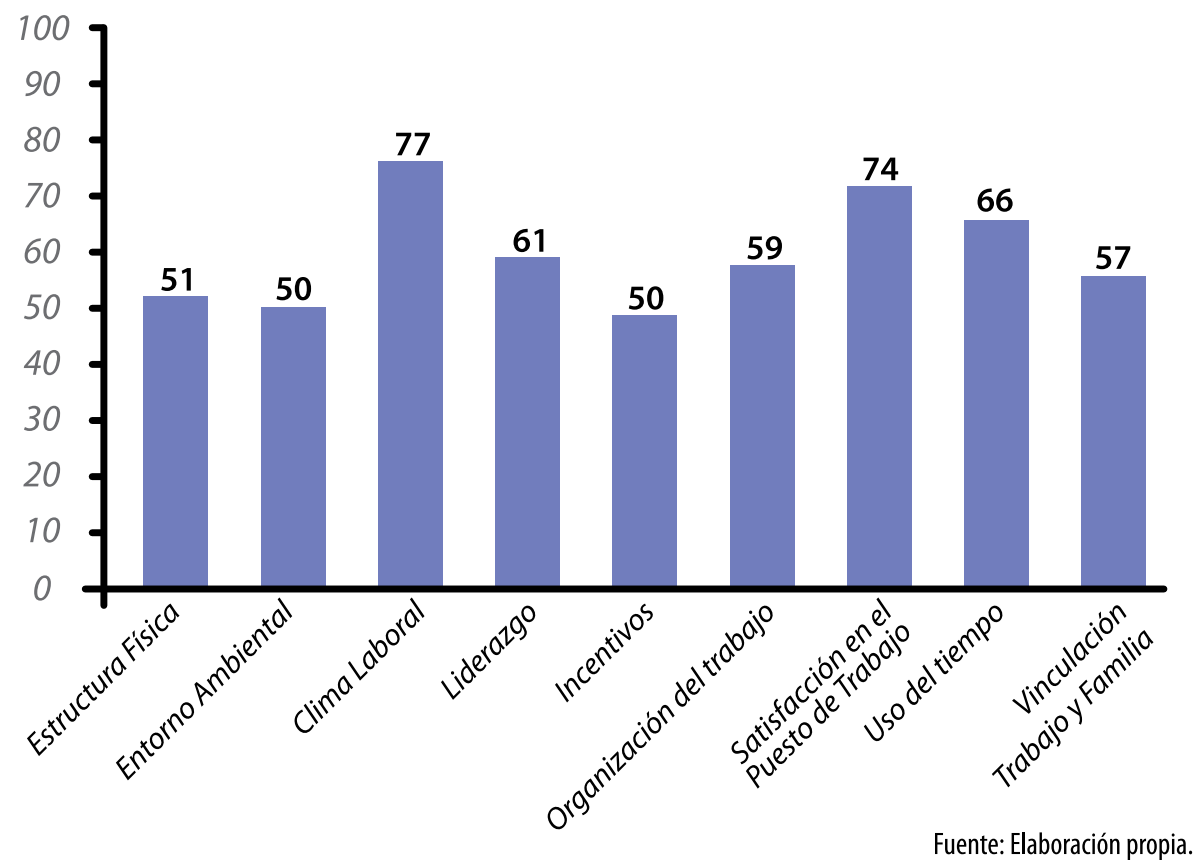


Por su parte los aspectos de más baja evaluación por parte de los funcionarios son los de entorno ambiental, incentivos, y estructura física. De acuerdo a los resultados presentados, se constata que las variables poseen evaluaciones medias muy cercanas a la línea de desaprobación (50 puntos).

\section{a. Condiciones Materiales}

De acuerdo a los datos arrojados por la encuesta calidad de vida, aplicada en la Municipalidad de Lo Barnechea, es posible apreciar que el nivel de satisfacción que poseen los funcionarios en las condiciones de materiales es apenas de suficiencia. Al observar las variables de Estructura Física y Entorno ambiental ambas poseen un nivel de satisfacción de 50 puntos.

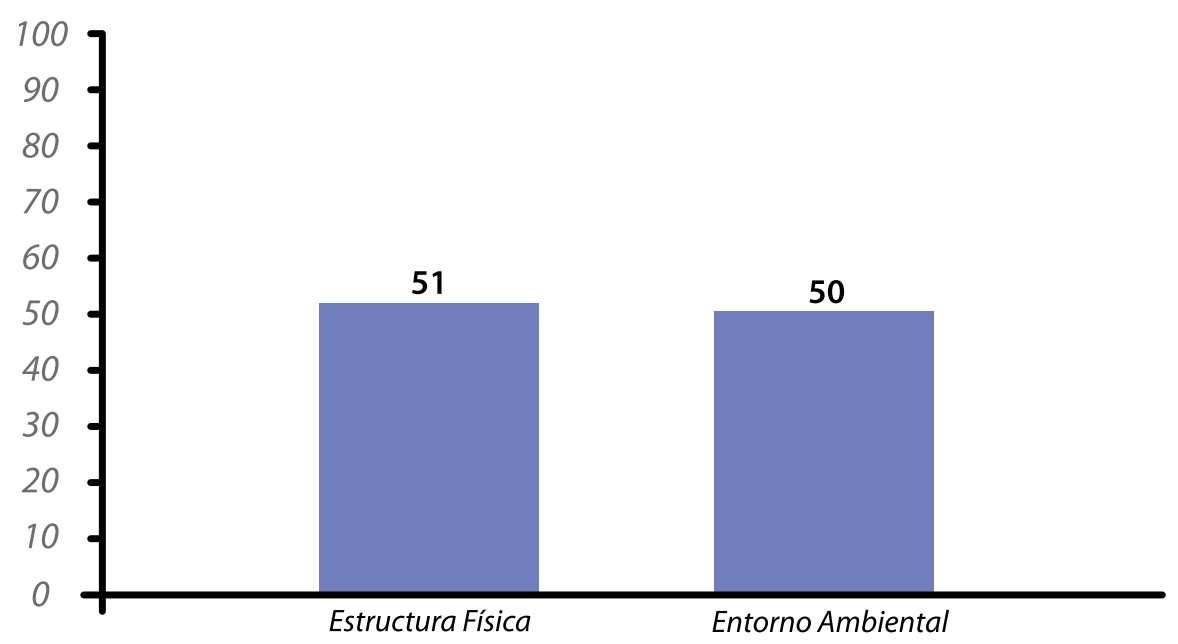


Para comprender los aspectos que determina las opiniones de los funcionarios frente a la estructura física y el entorno ambiental, a continuación se desarrolla un análisis descriptivo de las categorías incluidas en el análisis de ambas variables.

Como se ha señalado anteriormente, la percepción sobre estructura física ha sido medida a través de la percepción del equipamiento con el que cuentan los funcionarios para el desarrollo de sus labores (Mobiliario, artículos de oficina, implementos tecnológicos) y la satisfacción respecto de la pertinencia de la infraestructura para la realización de sus tareas (es- pacio de oficinas, espacio para reunirse con otros funcionarios, espacios recreativos, espacios de colación, servicios higiénicos).

De acuerdo a los resultados presentados en el Gráfico para la variable equipamiento el nivel de satisfacción es de 63 puntos por parte de los funcionarios del municipio. Al descomponer este dato por los indicadores medidos, es posible apreciar que los mejores evaluados son implementos tecnológicos (71 puntos) y Artículos de Oficina (65 puntos). Por otra parte, se muestra que el aspecto de más baja evaluación es el mobiliario (54 puntos).

Gráfico n³. Equipamiento. Nivel de Satisfacción Ptje 0-100

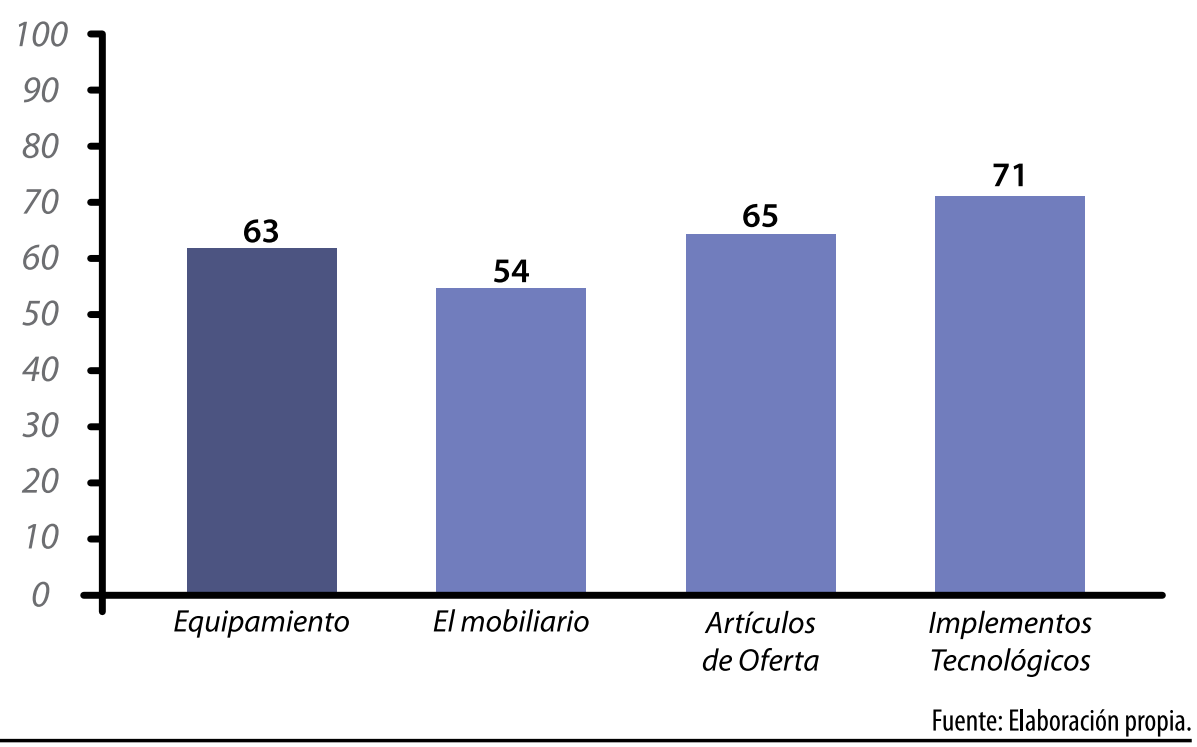


Frente a los niveles de satisfacción de la infraestructura, es posible apreciar que esa variable solo alcanza un nivel de satisfacción de 39 puntos (Insuficiencia - nivel inferior a la línea de aprobación de 50 puntos). De acuerdo a los resultados arrojados por sus indicadores esta baja evaluación se encuentra sustentada en la mala evaluación del espacio destinado a la alimentación (21 puntos), los espacios recreativos (25 puntos) y Espacios de Reunión (40 puntos).
Entre los aspectos mejor evaluados en la satisfacción con la infraestructura prestada por el municipio para el desarrollo laboral de los funcionarios, se encuentran, los espacios de oficina (55 puntos) y baños (55 puntos)

Gráfico n4. Satisfacción Infraestructura. Nivel de Satisfacción Ptje 0-100

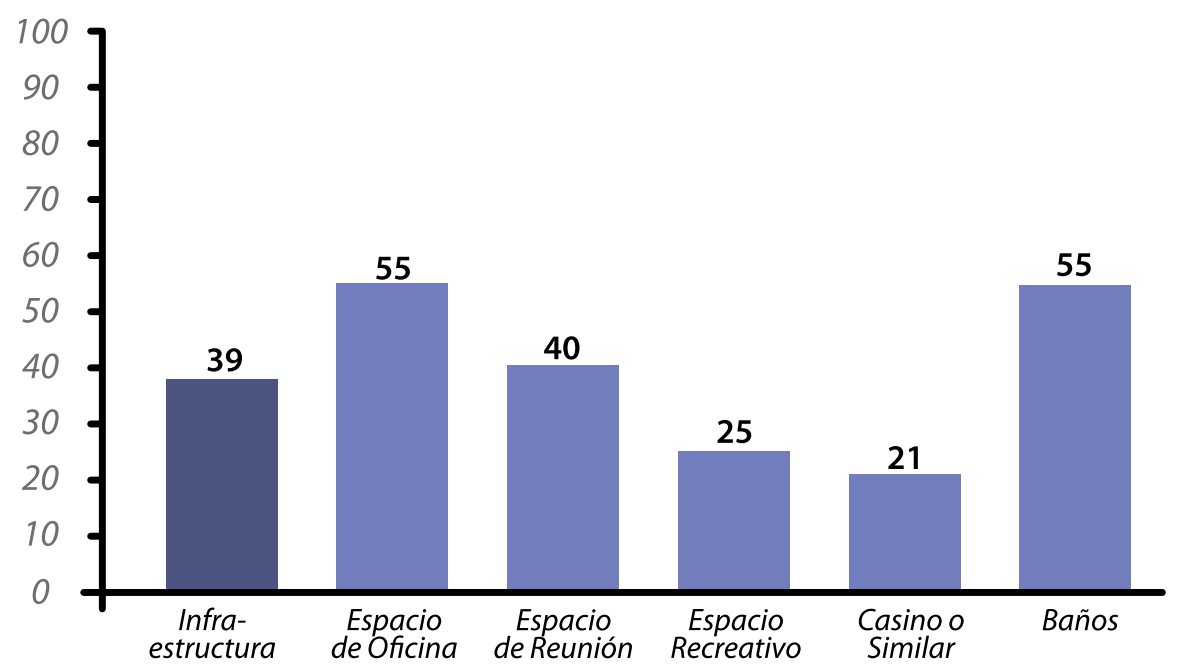

Fuente: Elaboración propia. 
Evaluación Entorno Ambiental

La evaluación del entorno ambiental en el que desempeñan sus funciones los trabajadores del municipio, ha sido medida a través de la percepción sobre la higiene de los espacios físicos y las condiciones ambientales con las cuales conviven los funcionarios municipales.

Al revisar la evaluación sobre la percepción de higiene en los espacios físico del municipio, es posible apreciar que en general el nivel de satisfacción de los funcionarios sólo alcanza a un nivel de suficiencia (51 puntos).
De acuerdo a los resultados arrojados por sus indicadores esta baja evaluación se encuentra sustentada en la mala evaluación de la higiene del espacio destinado a la alimentación (31 puntos) y lugares de descanso (42 puntos).

Entre los aspectos mejor evaluados en la satisfacción con respecto a la higiene de los lugares, se encuentran, los espacios de oficina (65 puntos) y baños (61 puntos).

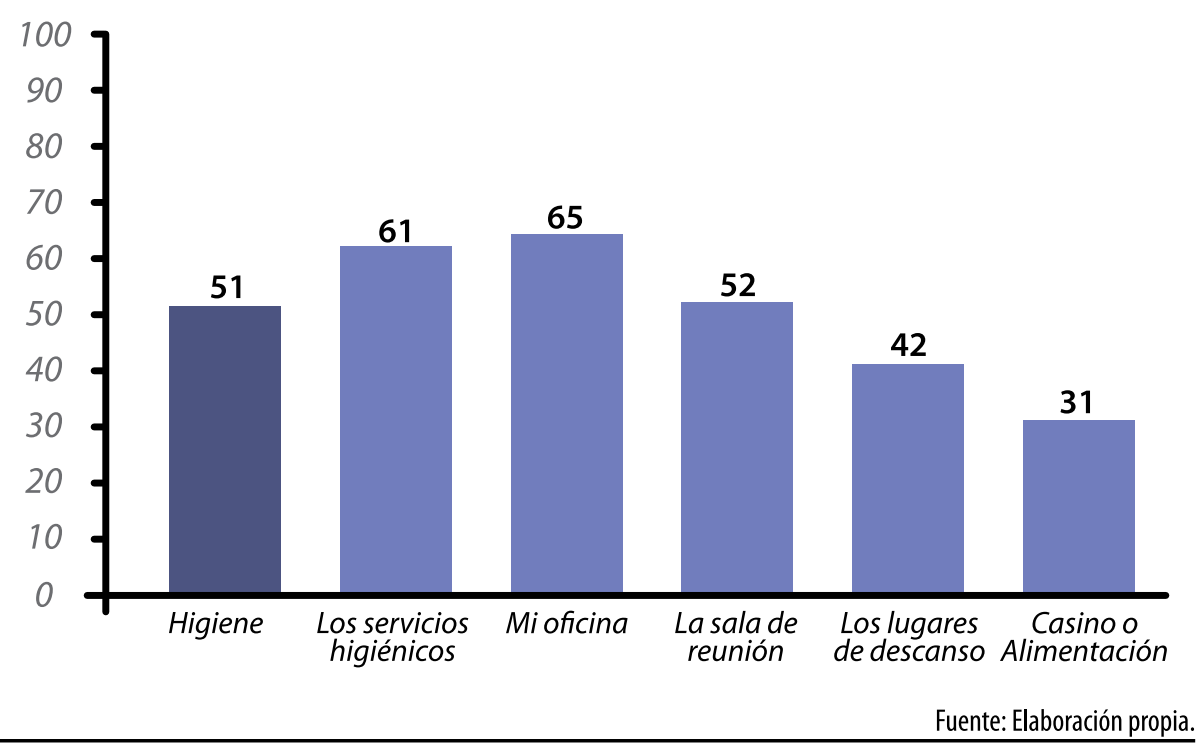


Las condiciones ambientales en promedio alcanzan sólo un nivel de satisfacción de 49 puntos, es decir, se encuentran por debajo de la línea de aprobación. Al revisar los indicadores que influyen en la menor satisfacción encontramos como aspectos más débilmente evaluados las condiciones de ventilación de los lugares de trabajo (39 puntos) y las condiciones de temperatura (42 puntos). En contraposición a la percepción sobre estos indicadores, se encuentra la sensación de ruido interno y externo las cuales alcanzan niveles de satisfacción de 55 puntos y 65 puntos respectivamente.

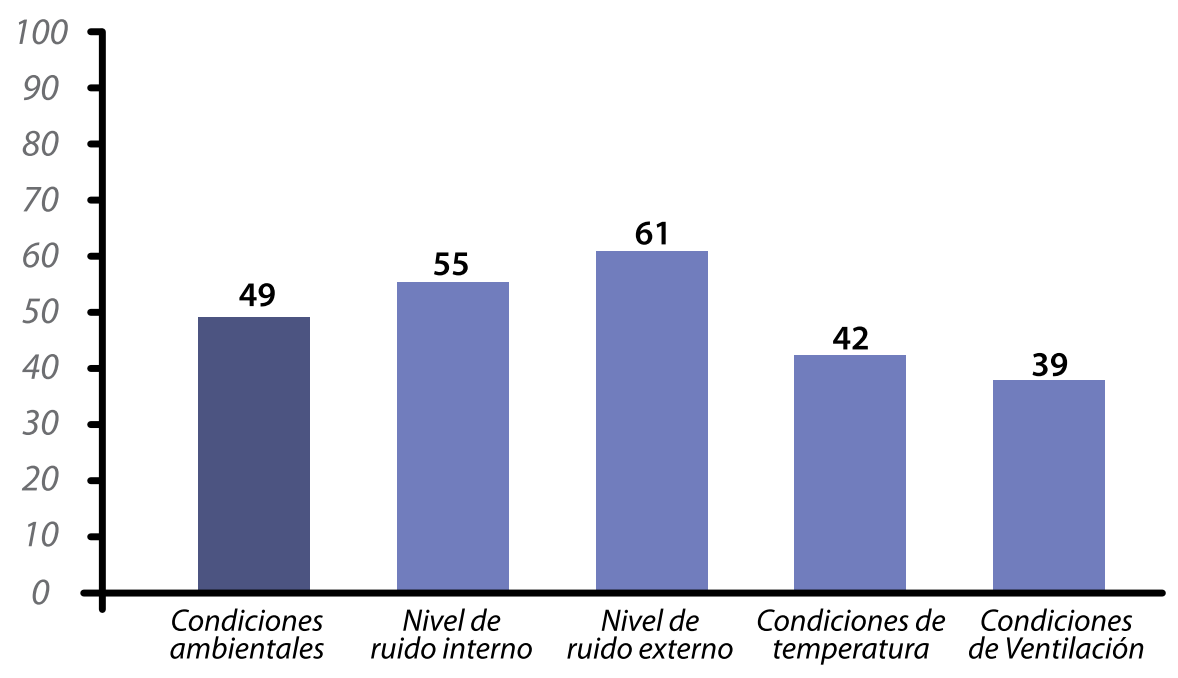

Fuente: Elaboración propia. 


\section{b. Condiciones organizacionales}

Frente a la dimensión condiciones organizacionales, es posible apreciar que para los funcionarios los aspectos con mejores niveles de aprobación son el clima laboral (77 puntos) y la satisfacción con el puesto de trabajo (74 puntos). En oposición a estas variables se encuentra los incentivos con 50 puntos de aprobación.
En rangos intermedios de evaluación es posible encontrar las percepciones sobre el uso del tiempo (66 puntos), liderazgo (61 puntos), organización del trabajo (59 puntos) y Vinculación de trabajo y familia (57 puntos).

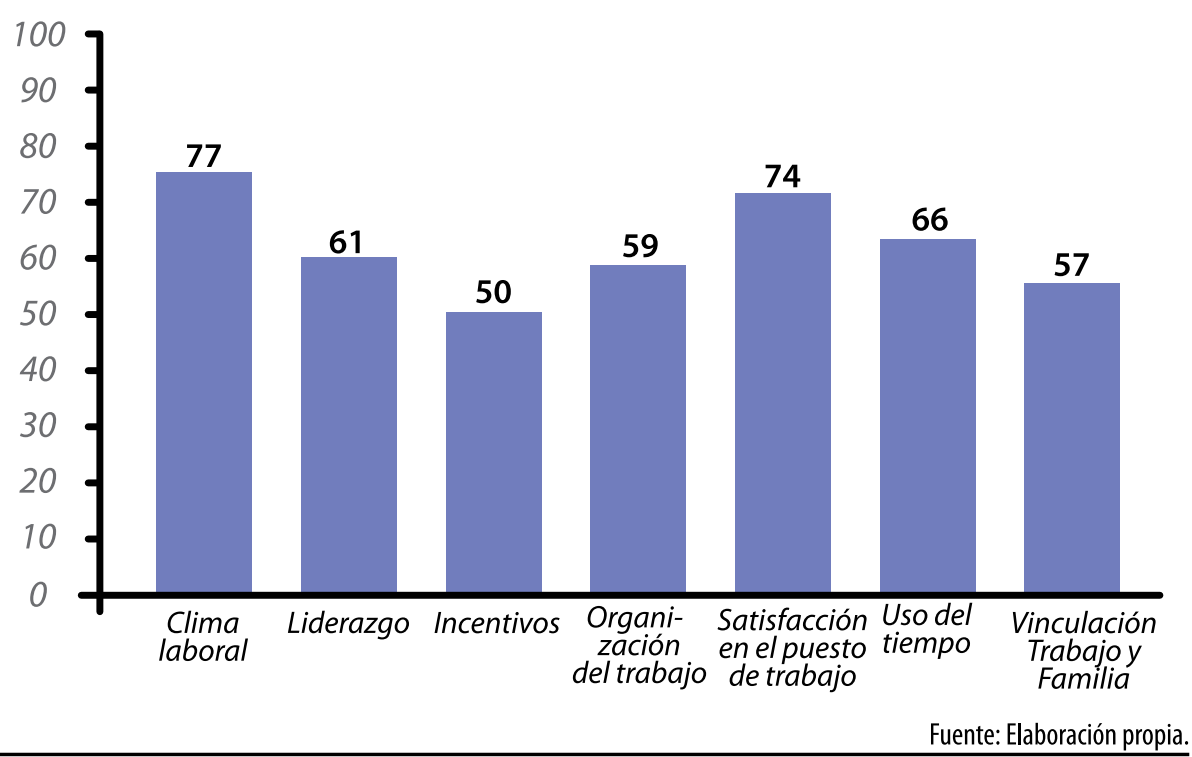


A continuación, se presentan un análisis descriptivo de las categorías incluidas en el análisis, destinadas a comprender las opiniones vertidas por los funcionarios municipales para cada una de las variables.

\section{Clima Laboral}

Como se observó en el Gráfico, la percepción sobre el clima laboral al interior del municipio es uno de los aspectos con mayor nivel de aprobación (77 puntos).
Para la medición de este aspecto se distinguió entre el clima laboral de la unidad del funcionario, el clima laboral en relación con otras unidades y el clima laboral establecido entre el funcionario y el Concejo municipal. De los tres ámbitos evaluados, los referidos al clima en el departamento de trabajo y la vinculación con otros departamentos alcanzan evaluaciones similares con 84 puntos y 80 puntos de aprobación respectivamente. En la evaluación general al clima laboral entre funcionarios y Concejo municipal la percepción de aprobación disminuye a 66 puntos.

Gráfico n8. Clima Laboral. Nivel de Satisfacción Ptje 0-100

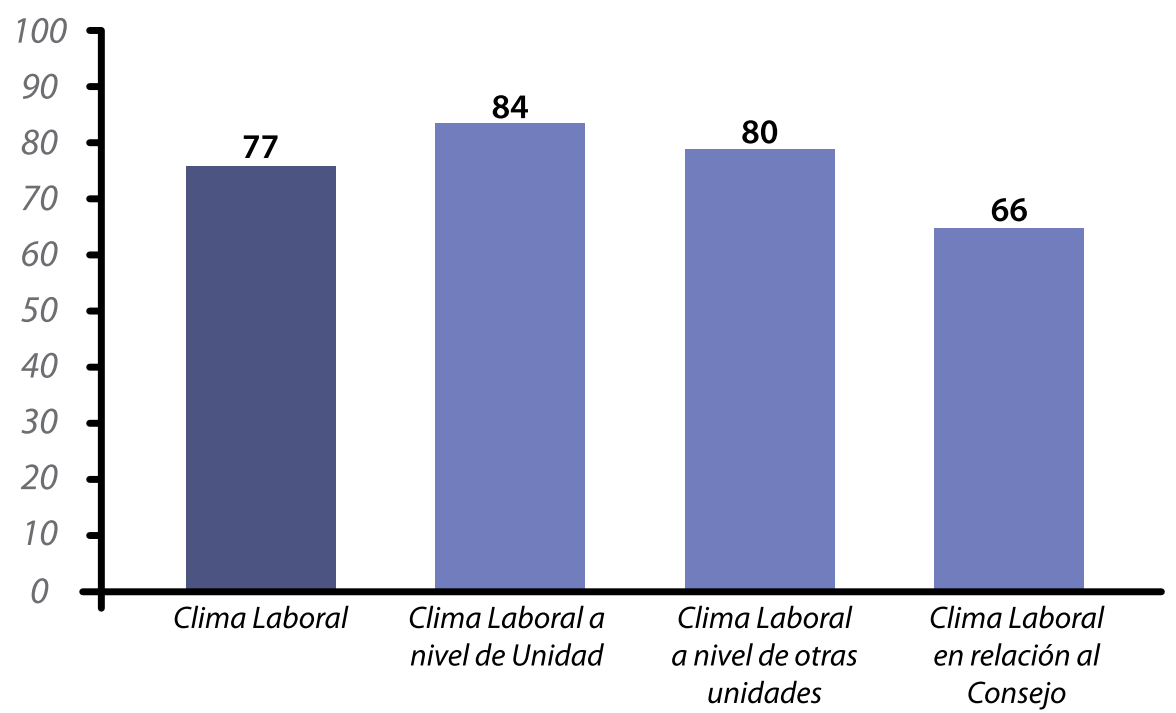

Fuente: Elaboración propia. 
De acuerdo a los resultados de la evaluación del clima a nivel de unidad de trabajo, se observa que el nivel de satisfacción declarado por los funcionarios es alto, donde se mantiene una buena relación de respeto y de colaboración con sus jefes directos (83 puntos), como con los pares de la misma unidad (85 puntos).

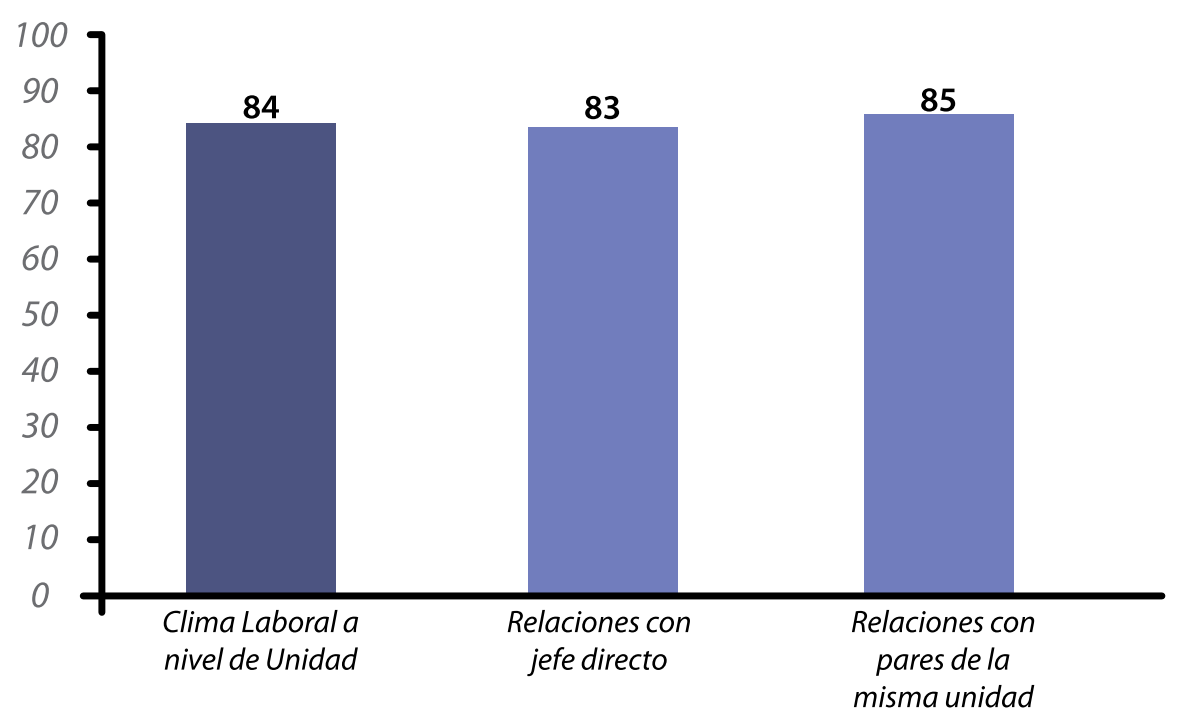

Fuente: Elaboración propia. 
Por otra parte, al evaluar los resultados sobre el clima laboral con otras unidades, se aprecia que las mayores evaluaciones se encuentran en las relaciones con los pares de otras unidades (85 puntos aprobación). Asimismo, se percibe una disminución en el porcentaje de aprobación al revisar los resultados de las relaciones con jefes de otros departamentos (80 puntos). Esta diferencia se acrecienta al comparar la evaluación promedio con la precepción de los funcionarios hacia la relación con los directores de servicio, alcanzando 75 puntos de aprobación.

Gráfico n¹0. Clima Laboral a nivel de otras unidades. Nivel de Satisfacción Ptje 0-100

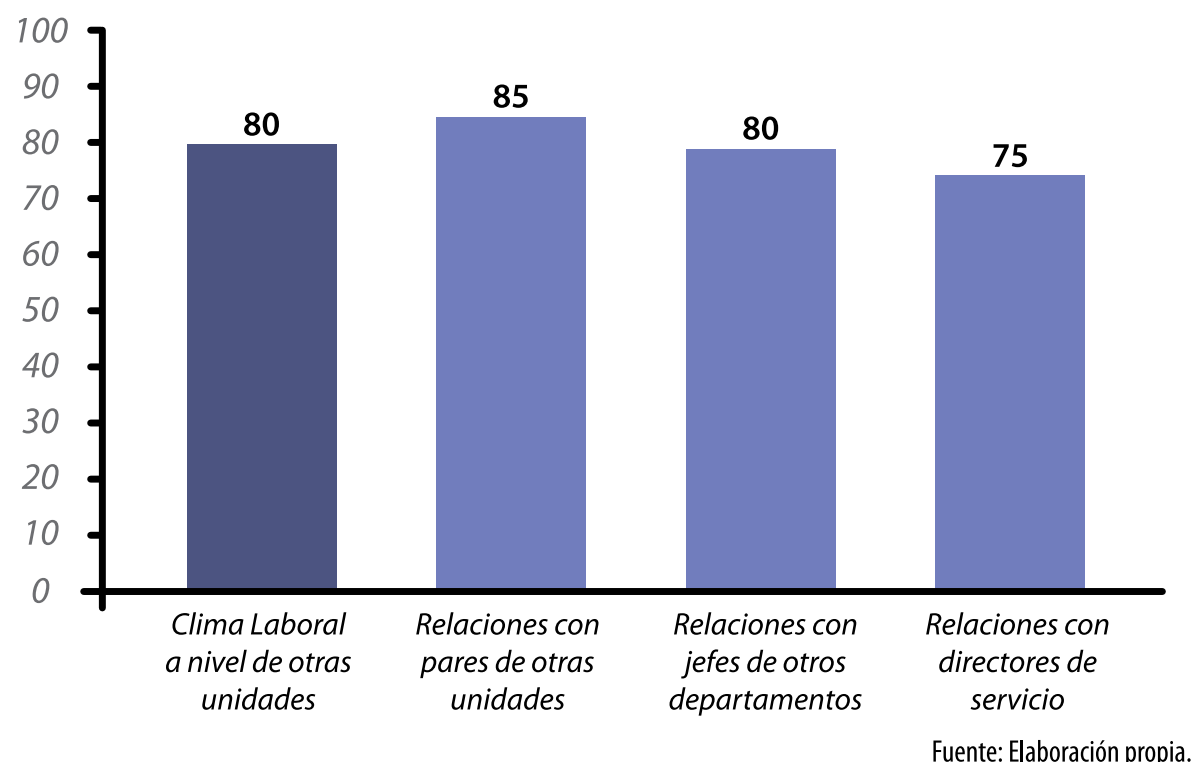


Dentro de la dimensión Clima Laboral, la percepción respecto a las autoridades municipales muestra el nivel relativo más bajo de aprobación (66 puntos). Al evaluar la relación que tienen los funcionarios con el alcalde el nivel de aprobación es de 69 puntos, descendiendo a 62 puntos cuando se evalúa la relación que tienen los funcionarios con los Concejales.
En resumen los resultados sobre el clima laboral, a nivel general presentan buenas evaluaciones para los tres ámbitos evaluados. La disminución en las evaluaciones registradas se vincula principalmente a la percepción sostenida por los funcionarios hacia los jefes de unidades y los directores de servicio y la relación con los concejales.

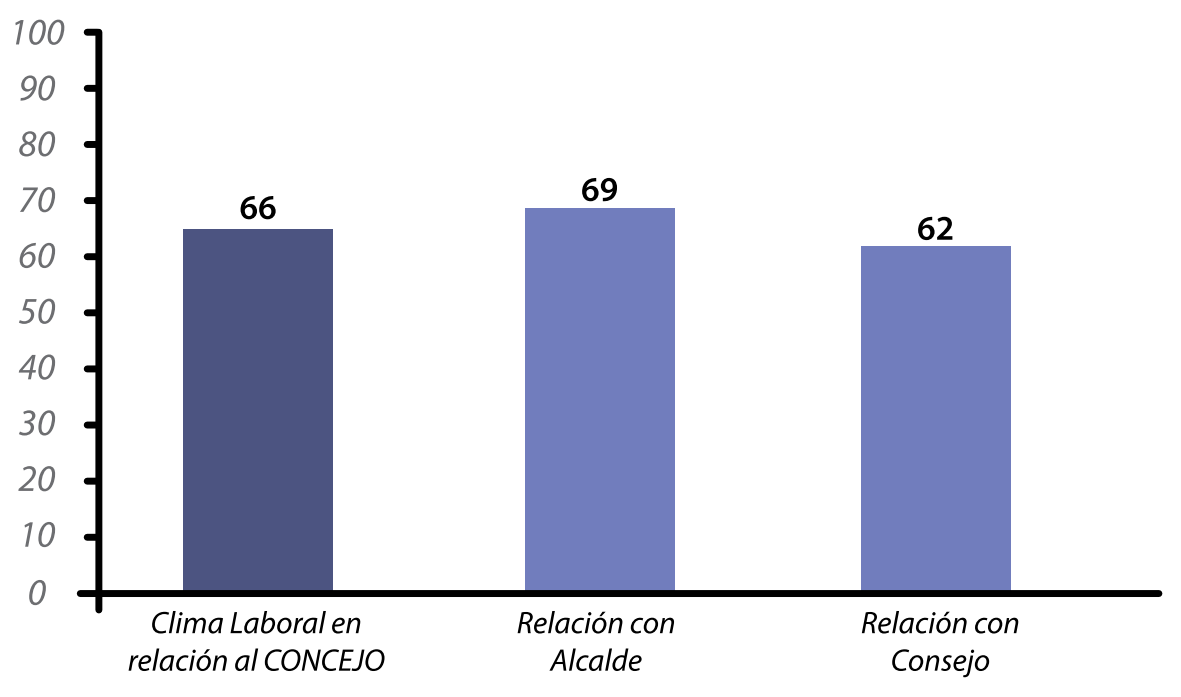




\section{Liderazgo}

Para la evaluación del liderazgo se midió la percepción de los trabajadores municipales sobre dos aspectos. El primero de ellos tiene relación con el Liderazgo del Alcalde entendido como su capacidad de generar compromiso sobre los funcionarios y su facultad de optimizar los procesos para el desempeño de los funcionarios. Otro aspecto evaluado es el liderazgo de la jefatura directa comprendida como la capacidad de motivación y su rol facilitador para el cumplimiento de las tareas. En una comparación de las variables evaluadas, el liderazgo de los jefes directos posee mayor nivel de aprobación (68 puntos) que el liderazgo del Alcalde (54 puntos).

Gráfico n¹2. Liderazgo. Nivel de Satisfacción Ptje 0-100

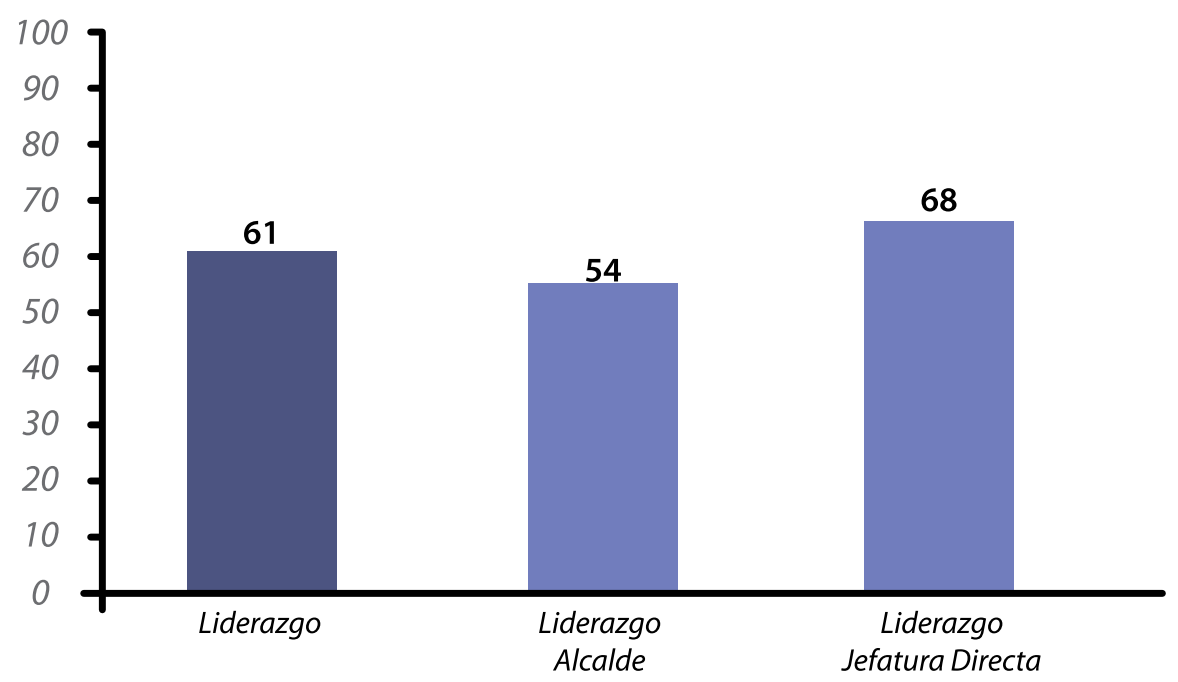

Fuente: Elaboración propia. 
Al revisar la evaluación del liderazgo alcaldicio, se aprecia que el nivel de evaluación de las variables componentes es bastante homogéneas entre sí, aunque el ámbito mejor evaluado es su capacidad de optimizar los procesos pare el cumplimiento de tareas por parte de los funcionarios (55 puntos), no se diferencia significativamente del indicador que mide la capacidad de genera compromiso en los funcionarios (52 puntos)..

Gráfico n¹3. Liderazgo Alcalde. Nivel de Satisfacción Ptje 0-100

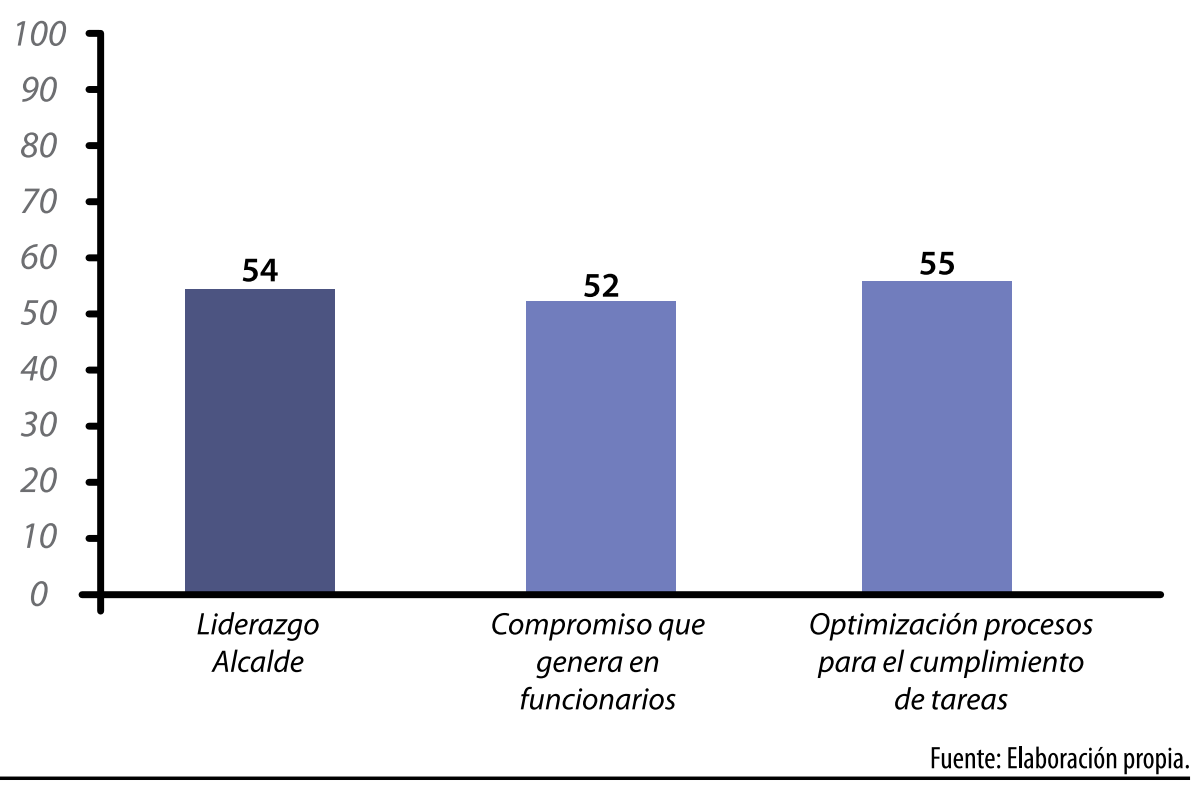


Frente a la evaluación del liderazgo de las jefaturas directas, los funcionarios otorgaron un 70 puntos de aprobación a la capacidad de optimizar los procesos destinados a facilitar el cumplimiento de tareas por parte de los trabajadores municipales. En el caso de la medición del compromiso que generan sobre los funcionarios la evaluación no difiere de la anterior llegando a 65 puntos de aprobación.

Gráfico n¹4. Liderazgo Jefatura Directa. Nivel de Satisfacción Ptje 0-100

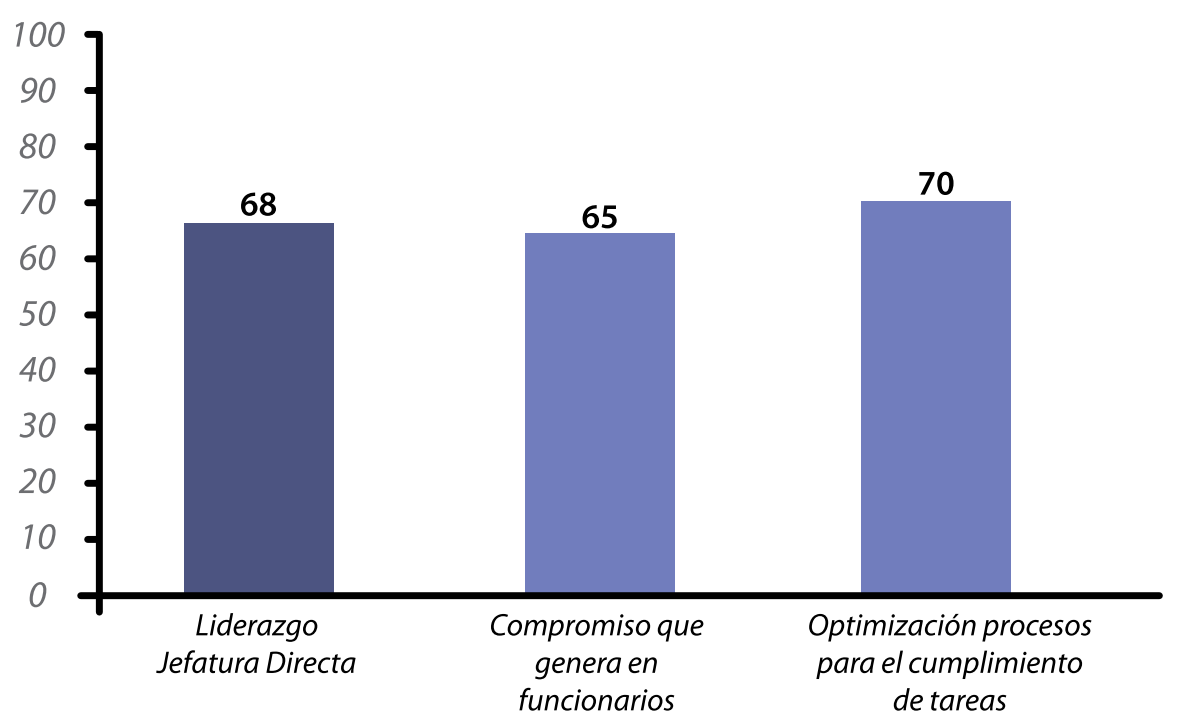

Fuente: Elaboración propia. 


\section{Incentivos}

Los incentivos son el puntaje más bajo en la evaluación de las condiciones organizacionales de la municipalidad de Lo Barnechea y hacen alusión a la baja percepción que los funcionarios tienen de recibir o ser beneficiados con ellos. De éstos se entienden los incentivos que están explícitos por ley, como las anotaciones de mérito y demérito, los bonos por producción (Ley 19.803 asignación de mejoramiento de la gestión municipal) las capacitaciones y el ascenso por escalafón (desarrollo de carrera y movilidad). También existe una baja percepción en el otorgamiento de los incentivos implícitos que dependen de cada municipio como los beneficios sociales, convenios del municipio con empresas privadas, seguridad o estabilidad en el empleo, felicitaciones u elogios, pasantías y beneficios de salud.

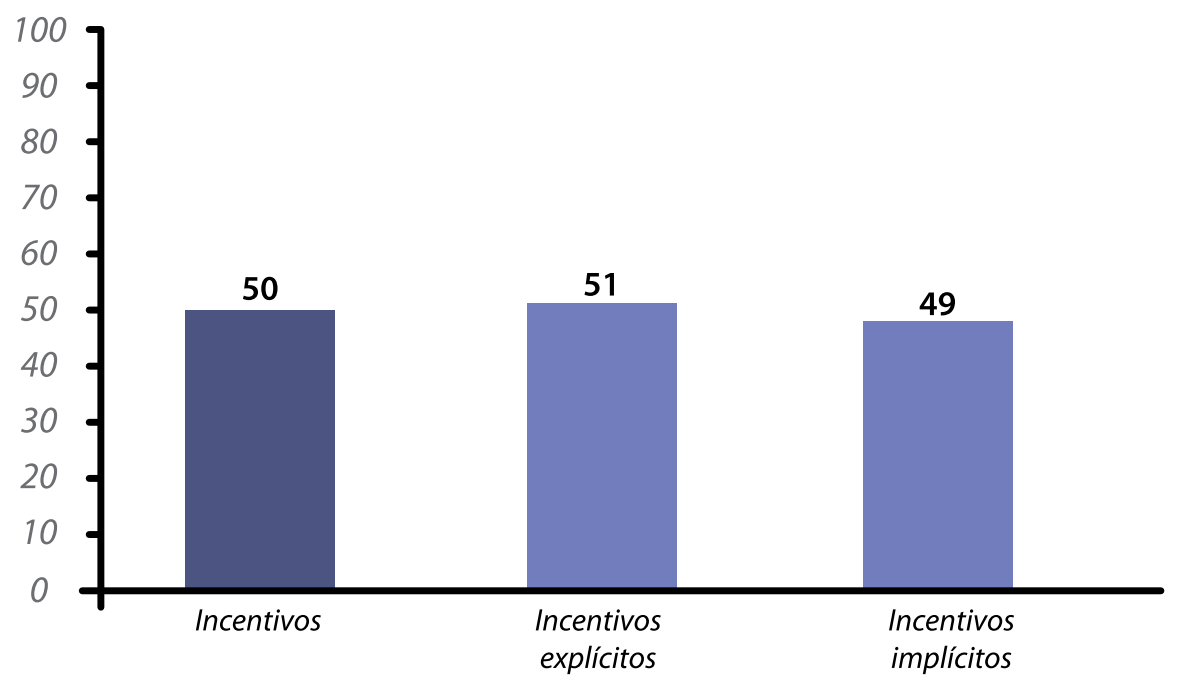


Los incentivos explícitos tienen mejor percepción para los funcionarios municipales, y están dados por capacitación (62 puntos) y los bonos de producción (59 puntos), luego están los que son dados por anotaciones de mérito y demérito (49 puntos). Los que tienen una descenso significativo son los que son otorgados por ascenso de escalafón (32 puntos).

Gráfico n 16. Incentivos explícitos. Nivel de Satisfacción Ptje 0-100

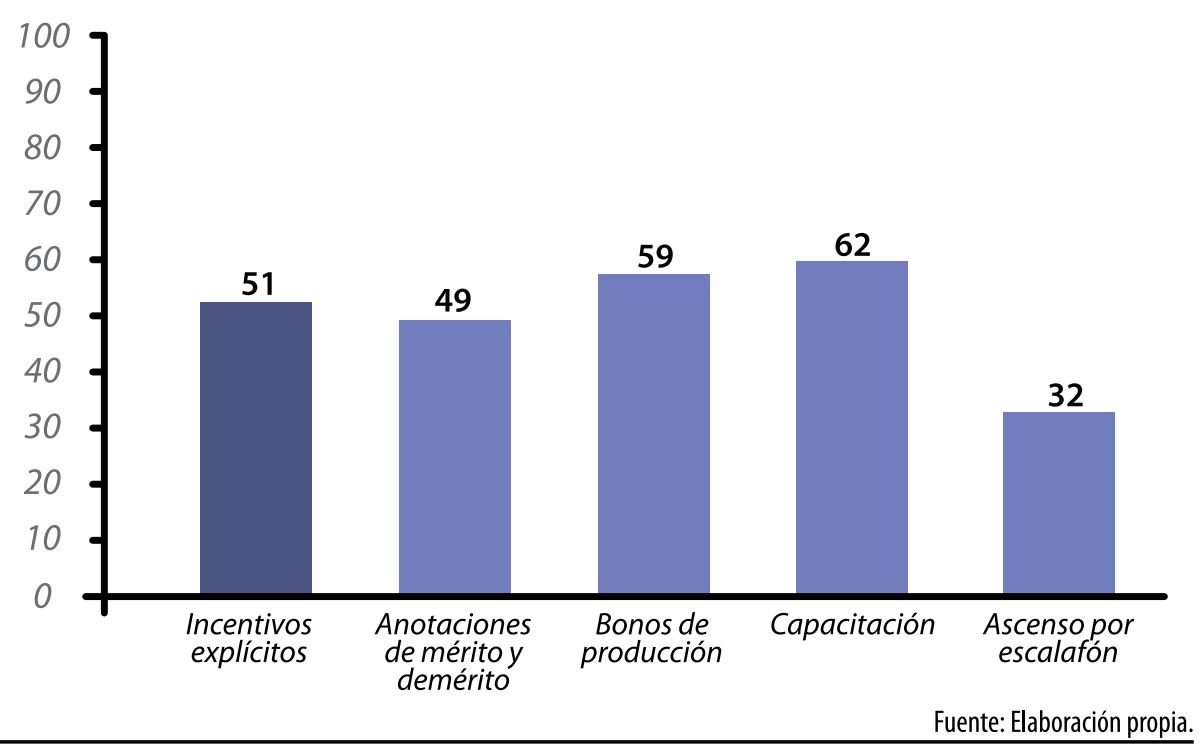


Por otra parte, frente a los incentivos implícitos se puede observar que casi todas las variables poseen niveles de aprobación menores al punto de corte (50 puntos), excepto el indicador de estabilidad del empleo que posee un nivel de 66 puntos.

Gráfico n¹7. Incentivos implícitos. Nivel de Satisfacción Ptje 0-100

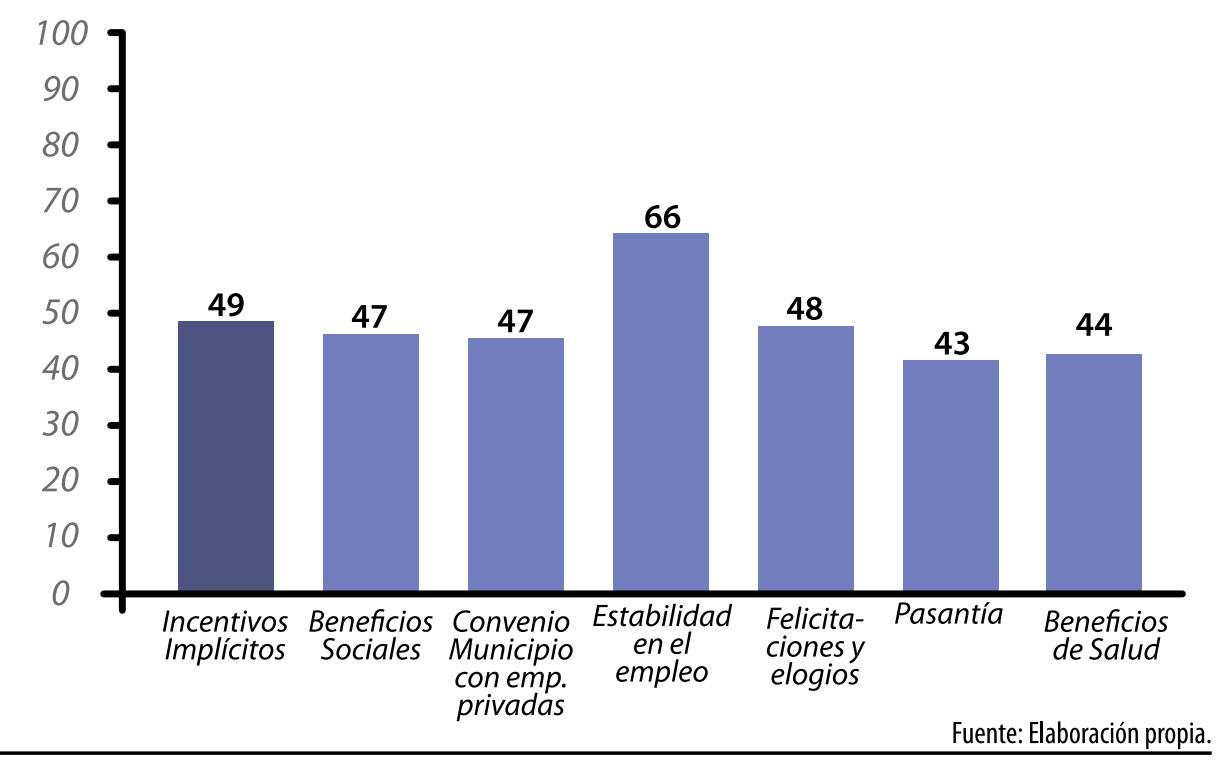




\section{Organización del trabajo}

Al revisar los resultados arrojados para la organización del trabajo, es posible observar que en orden de evaluación el indicador con una mayor aprobación de los funcionarios municipales es el de procedimientos (77 puntos), seguido por sistemas de comunicación (59 puntos) normas y reglamentos (55 puntos), pertinencia del sistema de control (55 puntos) y por último plan estratégico/ PLADECO y coordinación de actividades de trabajo (52 puntos).

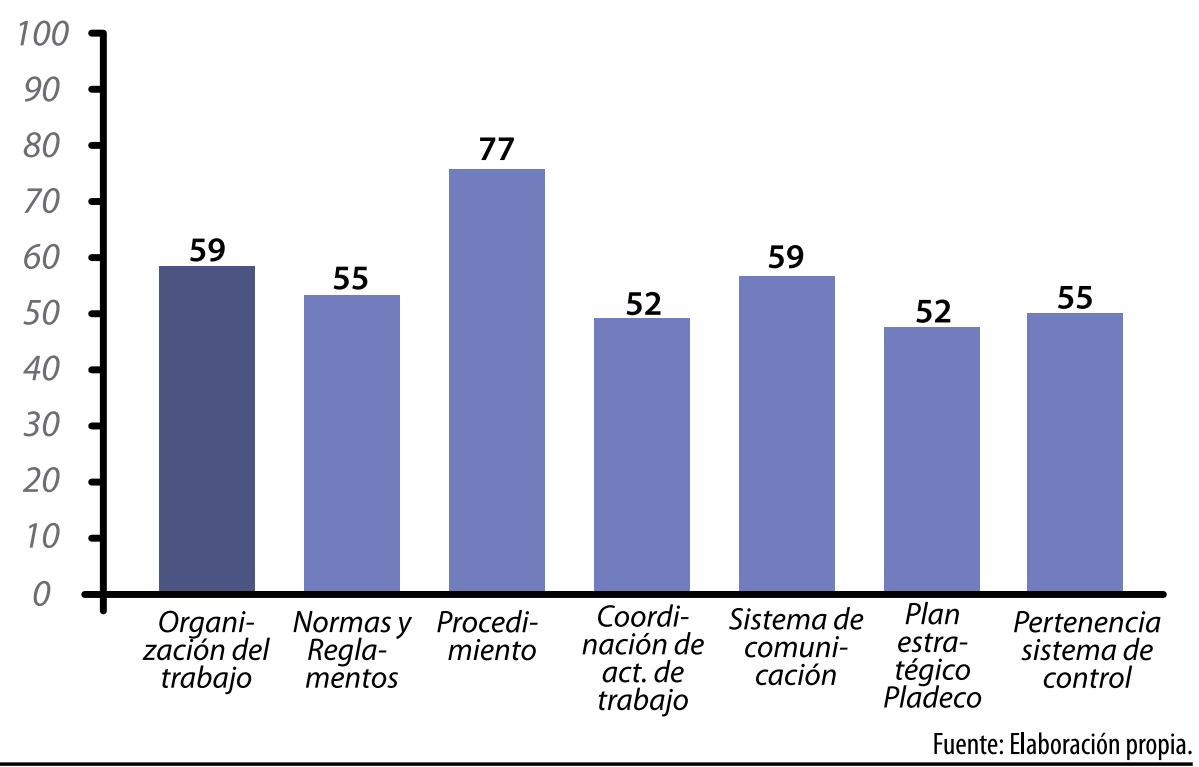




\section{Uso del tiempo}

De acuerdo a la percepción de los funcionarios respecto al uso del tiempo, estos calificaron con un nivel de aprobación de 72 puntos el horario de la Jornada laboral, seguido de 68 puntos en horas extras y por último con 58 puntos el nivel de aprobación de los períodos de descanso. Como dato a destacar de esta medición se encuentra el alto nivel de aprobación por parte de los funcionarios ante la pregunta por lo adecuado de su jornada laboral.
Por otro lado, a pesar de la buena evaluación a la jornada laboral, existe una sensación en los funcionarios de que los periodos de descanso no son suficientes. Esta percepción podría ser explicada por el nivel de carga laboral o la falta de vacaciones.

Gráfico n 19. Uso del tiempo. Nivel de Satisfacción Ptje 0-100

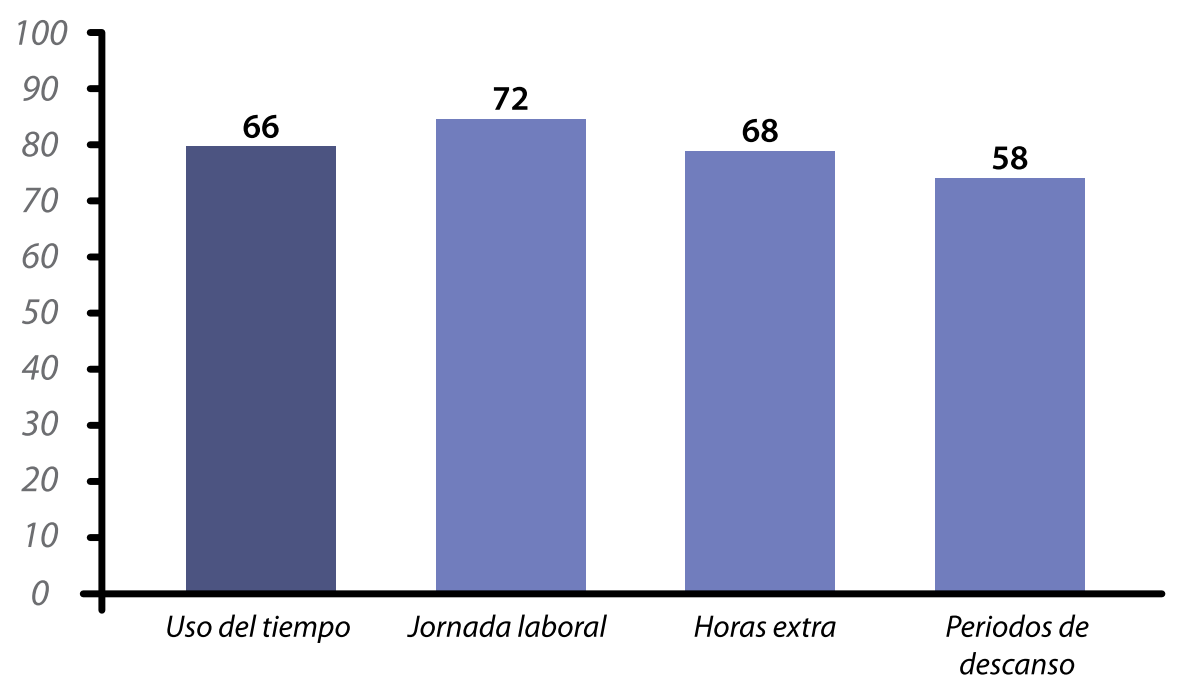

Fuente: Elaboración propia. 


\section{Satisfacción Puesto Laboral}

Existe una alta satisfacción del puesto de trabajo por parte de los funcionarios de la Municipalidad de Lo Barnechea, corroborado con una aprobación de 81 puntos que corresponde a la satisfacción respecto a sus tareas, a continuación, la relevancia del puesto de trabajo en que se encuentra (78 puntos), luego sigue con un 72 puntos el nivel de responsabilidad que sienten con éste, y por último la pertenencia que ellos tienen en relación a su puesto de trabajo con un 64 puntos.

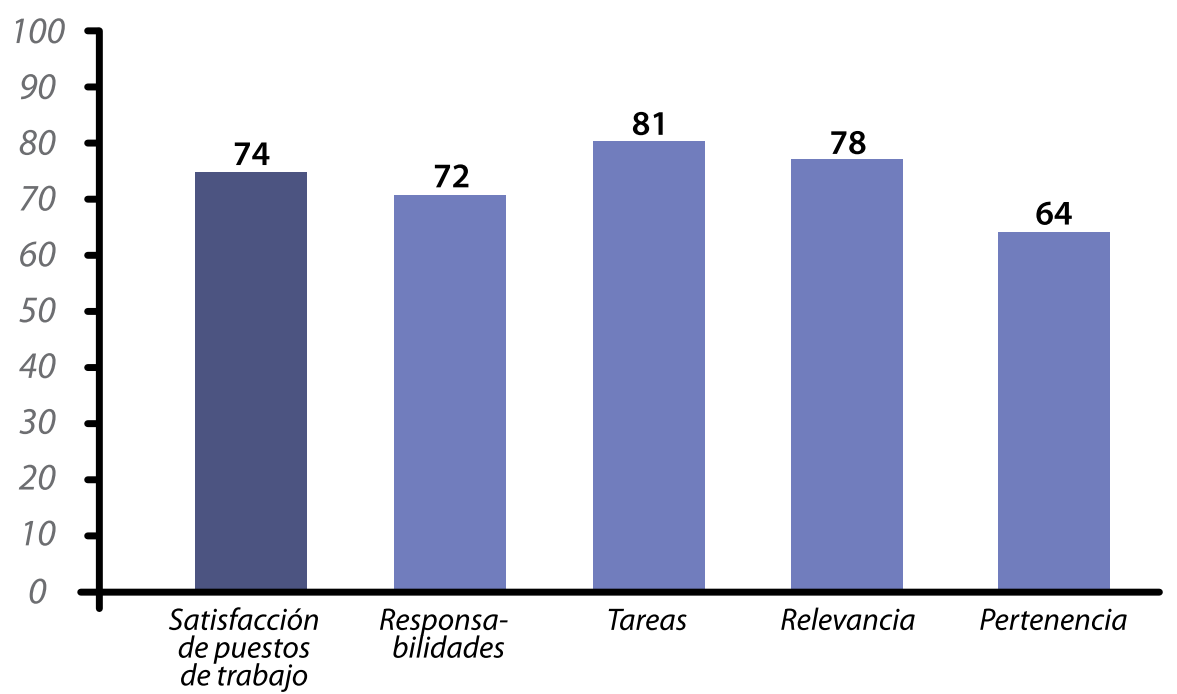

Fuente: Elaboración propia. 
Vinculación Trabajo y Familia

De acuerdo a lo establecido en el marco referencial de esta evaluación, en el ámbito privado uno de los aspectos más importantes de la calidad de vida laboral, es la vinculación que pueden realizar las organizaciones con el mundo privado de los trabajadores.
Al revisar los resultados de manera desagregada por indicador, es posible percatarse que los aspectos que mejor evalúan los funcionarios es el servicio de sala cuna o jardín infantil (67 puntos) y la flexibilidad de horarios (65 puntos). El único de los indicadores medidos que no alcanza una buena percepción desde los trabajadores, tiene relación con las actividades culturales para la familia ( 40 puntos).

Gráfico n²1. Vinculación trabajo y familia. Nivel de Satisfacción Ptje 0-100

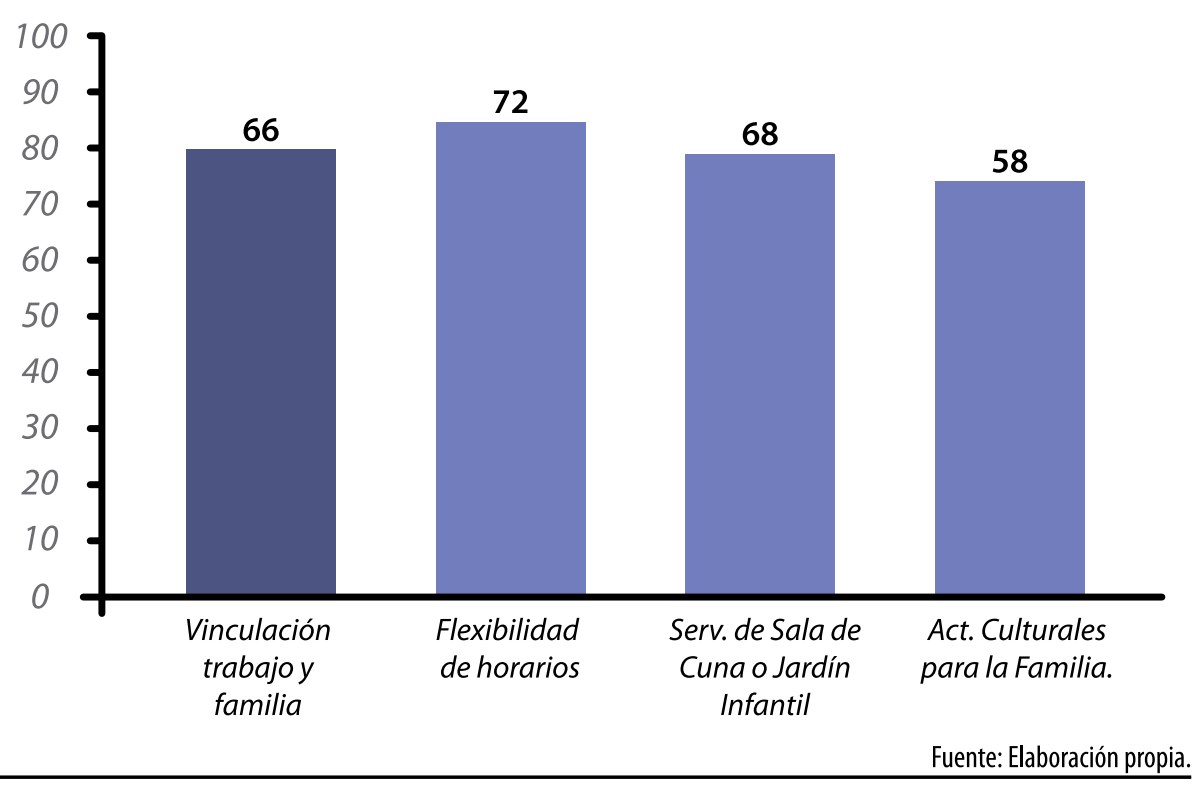




\section{CONCLUSIONES}

Tal como se mencionó en los antecedentes conceptuales del presente informe la evaluación realizada de Calidad de Vida Laboral en el Municipio de Lo Barnechea tiene como propósito central un diagnóstico sobre la situación del municipio en un momento específico con miras a orientar las posibilidades de mejoramiento de los niveles de satisfacción laboral de los funcionarios. En este sentido la presente evaluación no es pertinente con ejercicios de comparación con otros municipios o ranking por cuanto describe la construcción de los funcionarios con sus propias posiciones y expectativas respecto de su espacio de trabajo.

En cuanto a las nueve dimensiones evaluadas (Estructura Física, Entorno Ambiental, Clima Laboral, Liderazgo, Incentivos, Organización del trabajo, Tiempo, Satisfacción en el puesto de trabajo y Vinculación entre Trabajo y Vida Familiar) es posible caracterizarlas como Fortalezas, Debilidades, y Dimensiones con evaluación media según el puntaje obtenido en una escala de 0 a 100. Las dimensiones consideradas como fortalezas de la CVL en el municipio de Lo Barnechea son Clima Laboral (77 puntos), Satisfacción en el puesto de trabajo (74 puntos) y Uso del Tiempo (66); Las dimensiones consideradas como Debilidades son Entorno Ambiental (50), Estructura Física (51) e Incentivos (50); finalmente las evaluaciones con puntuaciones medias son Liderazgo (61) Organización del Trabajo (59) y Vinculación Trabajo y Familia (57).
En las dimensiones consideradas como fortalezas la dimensión Clima Laboral destaca con buenas evaluaciones sobre 80 puntos la mayor parte de los aspecto considerados (Clima en la unidad de trabajo, en relación con otras unidades), sólo presentaron resultados más bajos, dentro de un marco de alta aprobación, la relación con el Alcalde y Concejo. Con respecto a satisfacción en el puesto de trabajo destaca con buenas evaluaciones sobre 78 puntos los aspectos de tareas y relevancias. Por último, el uso del tiempo destaca con buenas evaluaciones la jornada de trabajo y las horas extras.

Respecto a las debilidades en cuanto CVL la Estructura Física, especialmente los aspectos referidos a la satisfacción de infraestructura donde la situación del casino o espacio similar y espacios recreativos es crítica y la falta de espacio en salas de reunión es preocupante. Esta situación se confirma con respecto a las condiciones ambientales, donde los lugares nombrados anteriormente muestran niveles de higiene preocupantes y las instalaciones presentan problemas de ventilación y aislación térmica. La segunda dimensión con niveles de evaluación negativa son los Incentivos donde se observan situaciones que dicen relación probablemente con situaciones estructurales del municipio como es el Ascenso por escalafón. Sin embargo, hay margen por crecer que dice relación con los incentivos implícitos que pueden ser gestionados desde el municipio (beneficios sociales, convenios con empresas privadas, beneficios de salud, entre otros). 
Hay dimensiones que se ubican en los niveles medios de calificación, pero que como se ha mostrado en el desarrollo del estudio son relevantes al momento de realizar una evaluación de conjunto. En estas se observan una suerte de equilibrio entre aspecto bien evaluados y otros evaluados de forma deficitaria. Con respecto a Liderazgo se observa un mayor desarrollo por parte de los jefes directos de oficina, mientras el Alcalde es percibido con un menor nivel de liderazgo. Con respecto a Organización del trabajo se aprecia el mayor desarrollo con respecto al conocimiento de procedimientos, mientras en los demás aspectos se comportan bastante homogéneos entre sí, presentando un nivel de desaprobación en promedio de $40 \%$. Por último, Vinculación Trabajo y Familia presenta dos aspectos bastantes desarrollados Sala Cuna y Flexibilidad de horarios, mientras muestra una fuerte debilidad en posibilidad de participar en actividades culturales.

\section{BIBLIOGRAFÍA}

- Barraza, F. (2006) “Calidad de Vida y Trabajo". Recuperado el 15 de marzo 2006 de la base de datos del Instituto Profesional Carlos Casanueva. Santiago. http://asimetcapacitacion.cl/calidad_vida.htm

- Blanco, A. (1985). “La calidad de vida: supuestos psicosociales". En Morales, J.F., Blanco, A., Huici, C. y Fenández, J.M. Psicología Social Aplicada. Bilbao: DDB.
- Casas, F. (1999). "Calidad de vida y calidad humana". Papeles del psicólogo, 74, pp. 46-54. Revista del Colegio Oficial de Psicólogos.

- Castillo, J.J y Prieto, C. (1990). Condiciones de trabajo: Hacia un enfoque renovador de la psicología del trabajo y de las Organizaciones. Madrid: Eudema.

- Cherms, A. y Davis, L. (1975) "Assessment of the state of the Art". En Navaja, J. (2003) “De la calidad de vida laboral a la gestión de calidad: Una aproximación psicosocial a la calidad como práctica de sujeción y dominación. Tesis para optar al título de doctor en psicología Social, Universidad Autónoma de Barcelona, BarceIona España. [online] Disponible en: http://www.tdx.cesca.es/TESIS_UAB/ AVAILABLE/TDX-0503104-

- CODELCO, (2006c) "Gestión 2006 de la calidad de vida". Documento on-line, disponible en: http://www. codelco.cl (intranet) [30/08/2006].

- Diener, E. (2000). Subjective wellbeing: the science of happiness and a proposal for a national index. American Psychologist, 55, 34-43.

- Diener, E. \& Seligman, M. E. P. (2004). Beyond money: Toward an economy of web-being. Psychological science in the public interest, 5(1), 1-26.

- Espinosa, M., Morris P. (2002). Calidad de vida en el trabajo: Percepciones de los trabajadores. Departamento de Estudios, Cuadernos de Investigación, № 19 Dirección del Trabajo, Santiago de Chile. 